\title{
The Hamstring/Quadriceps Ratio in Young Men and Its Relationship with the Functional Symmetry of the Lower Limb in Young Men
}

\author{
Piotr Tabor *, Dagmara Iwańska (D, Anna Mazurkiewicz, Czesław Urbanik and Andrzej Mastalerz
}

check for

updates

Citation: Tabor, P.; Iwańska, D.; Mazurkiewicz, A.; Urbanik, C.; Mastalerz, A. The

Hamstring/Quadriceps Ratio in Young Men and Its Relationship with the Functional Symmetry of the Lower Limb in Young Men. Symmetry 2021, 13, 2033. https://doi.org/ $10.3390 /$ sym 13112033

Academic Editor: Robert Sainburg

Received: 25 July 2021

Accepted: 22 October 2021

Published: 27 October 2021

Publisher's Note: MDPI stays neutral with regard to jurisdictional claims in published maps and institutional affiliations.

Copyright: (C) 2021 by the authors. Licensee MDPI, Basel, Switzerland. This article is an open access article distributed under the terms and conditions of the Creative Commons Attribution (CC BY) license (https:/ / creativecommons.org/licenses/by/ $4.0 /)$.
Departmen of Biomedical Science, Józef Piłsudski Univesity of Physical Education in Warsaw, 00-809 Warszawa, Poland; dagmara.iwanska@awf.edu.pl (D.I.); anna.mazurkiewicz@awf.edu.pl (A.M.); czeslaw.urbanik@awf.edu.pl (C.U.); rzej.mastalerz@awf.edu.pl (A.M.)

* Correspondence: piotr.tabor@awf.edu.pl

\begin{abstract}
The relationship of muscle strength symmetry with the symmetry of dynamic activities such as vertical jump (CMJ) and with symmetry of ranges of motion is ambiguous. Therefore, the aim of the current investigation was to assess the relationship between the flexor/extensor strength ratio and the range of motion of the knee joints and VGRF during jump in a sample of young healthy men. The sample consisted of 64 healthy, active men. The flexor and extensor torques and ranges of active and passive mobility of both knee joints were measured. Vertical ground reaction force (VGRF) was measured using two platforms. There were no significant correlations between the symmetry of muscle strength and the symmetry of ranges of motion and the symmetry of the VGRF. Therefore, using the cluster analysis, 4 subgroups were distinguished due to the size of the flexor/extensor ratio (H/Q ratio). Significant differences were found in the level of strength of the knee flexors between the clusters. Detailed analysis of muscle strength symmetry and VGRF symmetry seem to confirm the Leading Joint Hypothesis theory of motion control in multi-joint systems. It was found that the process of controlling movement by the nervous system compensates for the small asymmetries in the level of muscle strength in the knee flexors and extensors, as well as small asymmetries of VGRF.
\end{abstract}

Keywords: muscle force asymmetry; jump asymmetry; ranges of motion asymmetry; leading joint hypothesis

\section{Introduction}

In the assessment of muscle strength, the term symmetry refers not only to the difference between right and left limbs but also to the ratio of agonistic to antagonistic muscle strength of the same limb [1]. The ratio of the strength of the muscles acting antagonistically on a given joint determines its stability. Baratta et al. [2] also identified the importance of the antagonist coactivation pattern as necessary to support ligaments in maintaining joint stability, equalizing joint surface pressure distribution, and regulating mechanical resistance of the joint. The reduced coactivation pattern of the untrained antagonist with the hypertrophied muscle increases the risk of ligament damage and demonstrates the adaptive properties of the antagonist muscle in response to exercise. According to many authors, the assessment of the proportion of antagonistic muscles has a high diagnostic value and can be a suitable tool to monitor the rehabilitation and training process [3-5]. The value of the ratio depends on many factors, including the conditions in which the muscle works (angular velocities, type of work, body position), and in the training process, it can reflect the predisposition to injury [6]. However, it is not clear what the level of this indicator should be. It is considered that it should range between 50 and $80 \%$ and higher for fast movements $\left(180^{\circ} / \mathrm{s}\right)$ [7]. Furthermore, for the knee joint, it should be between $50-60 \%$ and for the hip joint, between $60-80 \%$. 
Steindler [8] generalized that the absolute strength of the knee extensor muscles should exceed the knee flexion strength by 3:2, i.e., Hcon/Qcon $=0.66$. Values ranging from 0.43 to 0.90 for this knee flexor/extensor ratio have been reported in the literature. The exact value depended on the angular velocity developed during the measurement, the testing position, and the tested group $[7,9,10]$. There seems to be little consensus on the normative value for this conventional $\mathrm{H} / \mathrm{Q}$ ratio, although 0.6 is the value that has gained some general acceptance. For example, Heiser et al. [11] concluded that injury prevention through detection of muscle imbalance should be based on a minimum Hcon/Qcon ratio of 0.60 at an angular velocity of $1.05 \mathrm{rad} \times \mathrm{s}^{-1}$. Knapik et al. [12] found that athletes with a $15 \%$ difference between the strength of right and left knee flexors were more likely to suffer non-contact lower extremity injuries. Similarly, Nadler et al. [13] found that flexor strength imbalance on the opposite side of the hip joint may be a predictor of lower back pain. In opposition to these findings, Bennell et al. [7] and Beukeboom et al. [14] presented data that failed to demonstrate the link between the strength asymmetry and injuries.

One test to determine the risk of injury to the knee joint is to assess the asymmetry of vertical ground reaction forces (VGRF) during the vertical jump (CMJ) [15-17]. The apparent asymmetry/symmetry during jumping tests is called functional asymmetry/symmetry [18]. However, the relationships of the level of muscle strength asymmetry with performance during jumping tests are not entirely clear $[19,20]$. In a simulation study by Yoshioka et al. [21] the authors found that a bilateral strength deficit of 10\% did not affect the jump height. Different conclusions were reached by Bailey et al. [20]. These authors presented data indicating that isometric strength asymmetry was associated with lower values of jump height for squat jump (SJ), countermovement jump (CMJ), and peak power (PP) at different loads. Bell et al. [22] linked strength and power asymmetry to a decline in jumping performance. Bailey et al. [20] also showed a negative relationship between jump height during $\mathrm{CMJ}$ and $\mathrm{CMJ}$ with $20 \mathrm{~kg}$ load and the level of muscle strength asymmetry developed during isometric contraction. They also demonstrated gender differences in the level of asymmetry [23]. On the contrary, Lockie et al. [24]) showed no significant relationship between the level of asymmetry of ground reaction forces during the vertical jump and $10 \mathrm{~m}$ running speed. Similarly, Hoffman et al. [25] found no relationship between the asymmetry of jump height on the right and left leg with the speed of running with change of direction.

It is also known that jump height positively correlates with countermovement depth to some extent [26]. This in turn will depend on the range of motion in the knee and ankle joints. Furthermore, Maloney et al. emphasized the complexity of the relationship of muscle stiffness with the range of motion and jump height [27].

In addition, the relationship between the symmetry of muscle strength and ranges of mobility with functional symmetry may also be an interesting issue from the point of view of motion control by the nervous system. Activities such as vertical jump are performed thanks to the multi-segment system of the lower limbs. Controlling this system is complicated. Several hypotheses have been put forward to explain the control of human movements. One of them assumes that the assumptions of optimal human movement control show that nerve commands to muscles are the result of the CNS solving the problem of optimizing a specific cost function [28]. Another theory proposes that the set of control commands required to execute each specific move is stored in memory [29]. The disadvantage of these approaches is that it is difficult to use either for practical application, i.e., to consider motion control during each specific movement, to formulate effective recommendations by trainers, or to optimize specific human movements. It seems that these doubts are generalized by the leading joint hypothesis $(\mathrm{LJH})$, which is based on the assumption that the CNS uses the biomechanical properties of the limbs to organize movement [30]. This theory can be applied to the control of the right and left limbs. Therefore, the aim of the current investigation was to assess the relationship between the flexor/extensor strength ratio and the range of motion of the knee joints and VGRF during jump in a sample of young healthy men. 


\section{Subjects and Methods}

The subjects were of 64 healthy men aged $20.2 \pm 0.66$ years, with body height of $182.2 \pm 5.52 \mathrm{~cm}$ and body mass of $79.4 \pm 10.37 \mathrm{~kg}$. They were second-year students of the University of Physical Education (teaching specialization) who were active for at least $1.5 \mathrm{~h}$ four times per week. The exclusion criteria included: no current injuries to the lower limbs and no length discrepancies, as measured in the upright position from the ground to the greater trochanter of the femur, $>1 \mathrm{~cm}$ [31]. The study was approved by the Regional Ethical Review Board at Józef Pisudski Universyty of Physical Education in Warsaw (SKE01-04/2021).

The passive (RoMpas) and active (RoMact) range of motion of in knee joints was assessed. The measurement was made with a goniometer in a standing position. During the RoMact measurement, the subject flexed the knee by himself. During the RoMpas measurement, the subject was helped to make maximum movement. The angle of $0^{\circ}$ meant full extension in the joint, whereas increasing its value was associated with greater flexion. The difference between passive and active ranges of motion (DIFpas-act) was calculated. A higher value of DIFpas-act indicated disorders of the knee extensors and flexors. The muscle torques developed by the flexors (Tflex) and extensors (Text) of the left and right knee joints were evaluated. The measurement was performed under static conditions in a sitting position and in the $90^{\circ}$ position in the knee joint according to the procedure proposed by Knapik et al. [12]. After the standard warm-up, the subjects performed two isometric contractions lasting 3-5 s with a rest break of $20 \mathrm{~s}$. The measurement was made using a momentometer, where the axis of the knee joint coincided with the axis of the device. Two measurements were taken and the mean value was used for analysis. The flexor/extensor strength ratio was calculated as $\mathrm{H} / \mathrm{Q}$ ratio $=(1-(\mathrm{Tflex} / \mathrm{Text})) \times 100 \%$, whereas the symmetry index between the left and right limbs was calculated as SI $=2 \times$ $(\mathrm{L}-\mathrm{R}) /(\mathrm{L}+\mathrm{R})[32]$. The greater the value of the $\mathrm{H} / \mathrm{Q}$ ratio meant greater strength of the extensors in relation to the flexors. Two Kistler piezoelectric platforms (9287 BA; BioWare 5.2.0.2; $400 \mathrm{~Hz}$ ) were used to measure the ground reaction force developed during a vertical countermovement jump involving the lower limbs (CMJ). Each participant performed 2 jumps while standing with each leg on separate platforms and also landing on two platforms. The value of vertical (Iver) and frontal (Ifront) force impulse, and maximum values of ground reaction force (VGRFmax) were calculated. The jump height (hmax), the countermovement depth (hmin), the relative average power (Pav), and maximum power (Pmax) were calculated according to the procedure given by Gajewski et al. [33]. If the jump height of the two measurements was similar, the averaged parameters were entered into the analysis. In the case of noticeably weaker performance of one of the tests, better results were used for the analysis. In the case of maximum strength, the symmetry of the ground reaction forces was evaluated using the index proposed by Herzog et al. (SI VGRF $=2 \times(\mathrm{L}-\mathrm{R}) /(\mathrm{L}+\mathrm{R}))$ [32]. The symmetry of the forces generated by the left and right limbs was evaluated using the index proposed by Nigg et al. [34]. It has been shown in the literature that continuous indices are more useful for assessing the asymmetry of dynamic activities than discrete indices [35].

\section{Statistical Method}

In the statistical analysis, the level of significance of differences between the right and left limbs was verified using one-way analysis of variance (ANOVA). As the data were normally distributed, the interrelationships between range of motion and VGRF symmetry were examined by evaluating Pearson's simple correlation coefficients. The absolute values of the differences between left and right limbs in VGRFmax, I, Text, Tflex, RoMpas, and RoMact were used for the analysis.

Due to the lack of significant relationships between the above-mentioned groups of parameters, the tested group was characterized using cluster analysis. Agglomeration was performed using Ward's method and urban distance (Manhattan). Four clusters were distinguished based on $\mathrm{H} / \mathrm{Q}$ ratios for the left and right limbs. In the distinguished clusters, 
basic descriptive techniques were applied and one-way analysis of variance (ANOVA) was performed. For all tests, the probability level limits were set at $p=0.05$.

\section{Results}

In the study group, no statistically significant differences were found between the left and right lower limbs in terms of range of motion and VGRF (Table 1). Only in the case of flexor strength (Tflex) there was a statistical trend of differences $(p=0.0529)$. In most cases, the values of symmetry coefficients did not exceed $11 \%$.

Table 1. Mean values and standard deviations of parameters determining symmetry.

\begin{tabular}{|c|c|c|c|c|}
\hline Parameter & Left & & Right & $\mathrm{F} ; p$ \\
\hline $\mathrm{VGRF}_{\max }[\mathrm{N}]$ & $832 \pm 174.6$ & & $822 \pm 168.8$ & $\mathrm{~F}=0.111 ; p=0.739$ \\
\hline SI VGRF $_{\max }[\%]$ & \multicolumn{3}{|c|}{$10 \pm 7.5$} & \multirow{3}{*}{$\mathrm{F}=0.032 ; p=0.858$} \\
\hline $\mathrm{I}_{\mathrm{ver}}[\mathrm{Ns}]$ & $433 \pm 70.7$ & & $430 \pm 65.2$ & \\
\hline $\mathrm{SI}_{\mathrm{R}(\mathrm{t})}[\%]$ & \multicolumn{3}{|c|}{$5 \pm 2.3$} & \\
\hline $\mathrm{T}_{\text {ext }}[\mathrm{Nm}]$ & $246 \pm 52.4$ & & $248 \pm 55.0$ & $\mathrm{~F}=0.033 ; p=0.856$ \\
\hline $\mathrm{SI}_{\text {ext }}[\%]$ & \multicolumn{3}{|c|}{$9 \pm 9.7$} & \\
\hline $\mathrm{T}_{\text {flex }}[\mathrm{Nm}]$ & $132 \pm 37.7$ & & $128 \pm 34.3$ & $\mathrm{~F}=0.405 ; p=0.529$ \\
\hline $\mathrm{SI}_{\text {flex }}[\%]$ & \multirow{2}{*}{\multicolumn{2}{|c|}{$11 \pm 8.5$}} & & \\
\hline $\mathrm{H} / \mathrm{Q}$ ratio [\%] & & & $46 \pm 14.6$ & $\mathrm{~F}=0.187 ; p=0.666$ \\
\hline $\operatorname{RoM}_{\text {pas }}\left[{ }^{\circ}\right]$ & \multirow{3}{*}{\multicolumn{2}{|c|}{$2 \pm 2.6$}} & $157 \pm 10.7$ & $\mathrm{~F}=0.20 ; p=0.658$ \\
\hline $\mathrm{SI}_{\text {pas }}[\%]$ & & & & \\
\hline RoMact $\left[{ }^{\circ}\right]$ & & & $121 \pm 9.7$ & $\mathrm{~F}=1.33 ; p=0.251$ \\
\hline $\mathrm{SI}_{\mathrm{act}}[\%]$ & \multirow{2}{*}{\multicolumn{2}{|c|}{$6 \pm 7.2$}} & & \\
\hline DIF pas-act $\left[{ }^{\circ}\right]$ & & & $36 \pm 16.7$ & $\mathrm{~F}=0.209 ; p=0.648$ \\
\hline $\mathrm{SI}_{\mathrm{DIF}}[\%]$ & \multicolumn{3}{|c|}{$20 \pm 13.2$} & \\
\hline
\end{tabular}

VGRF $_{\max }$-maximum vertical reaction force; SI VGRF max $_{\text {- symmetry index of maximum vertical reaction force }}$ $\mathrm{I}_{\mathrm{ver}}$ - vertical component impulse; $\mathrm{T}_{\text {ext }}$ - extensor muscle torque; $\mathrm{T}_{\text {flex }}$-flexor muscle torque; $\mathrm{SI}_{\mathrm{ext}}$ - $\mathrm{symmetry}$ index of extensor muscle torque; $\mathrm{SI}_{\text {flex }}$-symmetry index of flexor muscle torque; $\mathrm{H} / \mathrm{Q}$ ratio-flexor/extensor strength ratio; $\mathrm{RoM}_{\mathrm{pas}}$ - passive range of motion; RoM $\mathrm{Mct}_{\text {- }}$-active ranges of motion; $\mathrm{SI}_{\mathrm{pas}}$-symmetry index of passive range of motion; $\mathrm{SI}_{\mathrm{act}}$ — symmetry index of active range of motion; $\mathrm{DIF}_{\text {pas-act }}$ - difference between passive and active ranges of motion; $\mathrm{SI}_{\mathrm{DIF}}$ - symmetry index of difference between passive and active ranges of motion.

In order to search for the relationship between the magnitude of symmetry of range of motion and symmetry of VGRF, differences between the left and right lower limbs were calculated in terms of the maximum vertical reaction force (VGRFmax), vertical component impulse (Iver), extensor (Text) and flexor (Tflex) muscle torque of the knee joint, and passive (RoMpas) and active (RoMact) ranges of motion. These differences were correlated with each other. The values of Pearson's simple correlation coefficients did not show any statistically significant relationships of the discussed indices of asymmetry (Table 2).

Table 2. Values of Pearson's simple correlation coefficients and probability levels of variables characterizing symmetry of range of motion and VGRF.

\begin{tabular}{cccccc}
\hline Parameter & $\begin{array}{c}\text { D. L-R } \\
\mathbf{I}_{\text {ver }}\end{array}$ & $\begin{array}{c}\text { D. L-R } \\
\mathbf{T}_{\text {ext }}\end{array}$ & $\begin{array}{c}\text { D. L-R } \\
\mathbf{T}_{\text {flex }}\end{array}$ & $\begin{array}{c}\text { D. L-R } \\
\text { RoM }_{\text {pas }}\end{array}$ & $\begin{array}{c}\text { D. L-R } \\
\text { RoM }_{\text {act }}\end{array}$ \\
\hline D. L-R VGRF & 0.531 & -0.02 & 0.12 & -0.21 & -0.09 \\
D. L-R I & $p=0.000$ & & & & -0.23 \\
D. L-R T & & -0.05 & 0.002 & -0.13 & $p=0.072$ \\
D. L-R T & & & 0.10 & 0.0001 & 0.12 \\
D. L-R RoM & & & -0.09 & -0.04 \\
& & & & -0.31 \\
plex & & & & $p=0.013$ \\
\hline
\end{tabular}

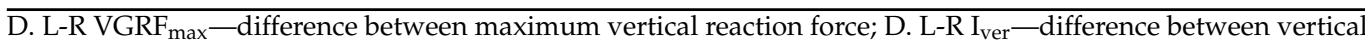
component impulse; D. L-R T ext - difference between extensor muscle torque; $\mathrm{D}$. L-R $\mathrm{T}_{\text {flex }}$ 一difference between flexor muscle torque; D. L-R RoM $M_{\text {pas }}$-difference between passive ranges of motion; D. L-R RoMact - difference between active ranges of motion. 
Therefore, multivariate descriptive techniques in the form of cluster analysis were used. Four clusters were identified due to the magnitude of $\mathrm{H} / \mathrm{Q}$ ratio (Figure 1). Six men were characterized by high muscle torques in flexors compared to the extensors of the knee joint in both the right and left lower limbs. Three participants had noticeable asymmetry of antagonistic muscle strength ratios, with markedly weaker flexors in the right limb. The remaining men were characterized by symmetrical muscle strength, but at different flexor/extensor ratios (clusters 3 and 4).

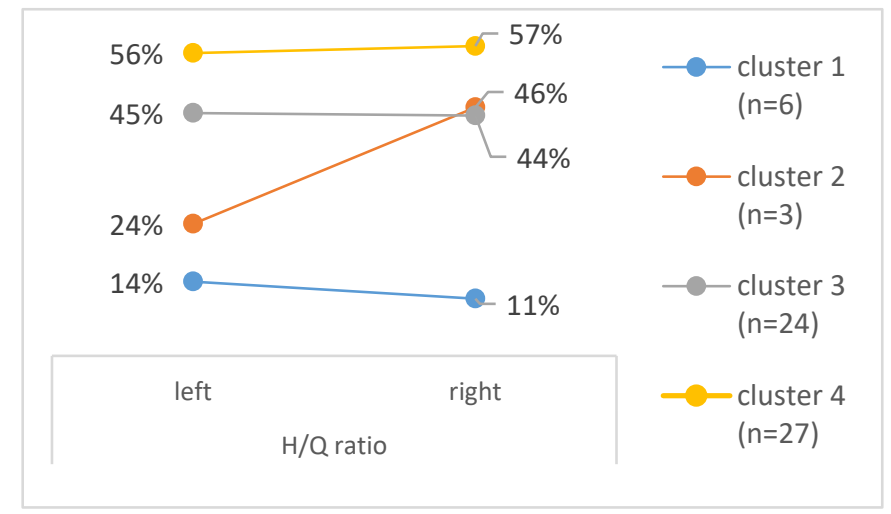

Figure 1. The clusters according to the values of the flexor/extensor strength ratio of the left and right knee joints (H/Q ratio). The numbers of participants in each cluster are given in brackets.

Since there were only 3 individuals in the second cluster, they were excluded from further analysis (Table 3). Based on one-way analysis of variance ANOVA, it was found that subjects from cluster 1 were significantly taller $(\mathrm{F}=6.72 ; p=0.024)$ than subjects from clusters $3(p=0.04)$ and $4(p=0.002)$. In terms of data characterizing the CMJ jump, there was no significant variation between clusters. A tendency for differences was found in the values of the transverse component impulse (Ifront) between the fourth and the remaining clusters $(\mathrm{F}=2.412 ; p=0.099)$.

Table 3. Characteristics of individual clusters in terms of somatic characteristics, vertical jump parameters, and symmetry range of motion and muscle strength; the " -" sign means right-sided advantage.

\begin{tabular}{|c|c|c|c|}
\hline \multirow{2}{*}{ Parameters } & \multicolumn{3}{|c|}{ Clusters } \\
\hline & $1(n=6)$ & $3(n=24)$ & $4(n=27)$ \\
\hline Body height & $188.5 \pm 6.72$ & $182.9 \pm 4.51$ & $180.5 \pm 4.89$ \\
\hline BMI & $23.4 \pm 2.56$ & $24.3 \pm 2.60$ & $23.6 \pm 2.95$ \\
\hline $\mathrm{h}_{\max }[\mathrm{m}]$ & $0.42 \pm 0.043$ & $0.43 \pm 0.052$ & $0.44 \pm 0.053$ \\
\hline $\mathrm{h}_{\min }[\mathrm{m}]$ & $0.38 \pm 0.064$ & $0.40 \pm 0.068$ & $0.39 \pm 0.082$ \\
\hline$P_{\max }[\mathrm{W} / \mathrm{kg}]$ & $31.4 \pm 5.13$ & $30.4 \pm 5.60$ & $31.1 \pm 4.84$ \\
\hline $\mathrm{P}_{\mathrm{av}}[\mathrm{W} / \mathrm{kg}]$ & $7.4 \pm 1.48$ & $6.6 \pm 1.57$ & $6.2 \pm 1.98$ \\
\hline $\mathrm{VGRF}_{\max }[\mathrm{N}]$ & $1788 \pm 254.4$ & $1686 \pm 314.2$ & $1624 \pm 362.3$ \\
\hline SI VGRF ${ }_{\max }[\%]$ & $3 \pm 18.7$ & $1 \pm 13.6$ & $1 \pm 10.3$ \\
\hline $\mathrm{I}_{\mathrm{ver}}[\mathrm{Ns}]$ & $878 \pm 131.3$ & $878 \pm 156.6$ & $854 \pm 109.6$ \\
\hline $\mathrm{SI}_{\mathrm{R}(\mathrm{t})}[\%]$ & $7 \pm 3.1$ & $6 \pm 2.3$ & $4 \pm 1.8$ \\
\hline $\mathrm{I}_{\text {front }}[\mathrm{Ns}]$ & $-14.4 \pm 14.21$ & $-7.3 \pm 14.70$ & $-2.5 \pm 10.49$ \\
\hline $\mathrm{T}_{\text {ext }}$ left $[\mathrm{Nm}]$ & $210 \pm 48.4$ & $247 \pm 45.2$ & $253 \pm 57.1$ \\
\hline $\mathrm{T}_{\text {ext }}$ right $[\mathrm{Nm}$ & $218 \pm 54.2$ & $255.3 \pm 47.7$ & $254.8 \pm 59.7$ \\
\hline SI ${ }_{\text {ext }}[\%]$ & $-4 \pm 10.0$ & $-3 \pm 10.4$ & $-0.3 \pm 9.9$ \\
\hline $\mathrm{T}_{\text {flex }}$ left $[\mathrm{Nm}]$ & $187 \pm 38.9$ & $136 \pm 22.8$ & $107 \pm 22.6$ \\
\hline $\mathrm{T}_{\text {flex }}$ right $[\mathrm{Nm}]$ & $188 \pm 51.0$ & $140 \pm 28.2$ & $111 \pm 27.7$ \\
\hline $\mathrm{SI}_{\text {flex }}[\%]$ & $0.2 \pm 12.3$ & $-2 \pm 13.3$ & $-3 \pm 13.7$ \\
\hline $\operatorname{RoM}_{\text {pas }}$ left $\left[{ }^{\circ}\right]$ & $155 \pm 5.3$ & $157 \pm 12.5$ & $155 \pm 11.1$ \\
\hline $\operatorname{RoM}_{\text {pas }}$ right $\left[{ }^{\circ}\right]$ & $156 \pm 5.3$ & $157 \pm 11.0$ & $156 \pm 11.1$ \\
\hline
\end{tabular}


Table 3. Cont.

\begin{tabular}{cccc}
\hline \multirow{2}{*}{ Parameters } & \multicolumn{3}{c}{ Clusters } \\
\cline { 2 - 4 } & $\mathbf{1}(\boldsymbol{n}=\mathbf{6})$ & $\mathbf{3}(\boldsymbol{n}=\mathbf{2 4})$ & $\mathbf{4}(\boldsymbol{n}=\mathbf{2 7})$ \\
\hline $\mathrm{SI}_{\text {pas }}[\%]$ & $-0.5 \pm 0.5$ & $-0.5 \pm 4.2$ & $-0.5 \pm 2.7$ \\
RoM $_{\text {act }}$ left $\left[{ }^{\circ}\right]$ & $125 \pm 7.6$ & $117.7 \pm 16.1$ & $118 \pm 14.5$ \\
RoM $_{\text {act }}$ right $\left[{ }^{\circ}\right]$ & $126 \pm 4.4$ & $122 \pm 9.9$ & $119 \pm 10.2$ \\
SI $_{\text {act }}[\%]$ & $-0.9 \pm 4.1$ & $-4 \pm 9.1$ & -1.19 .6 \\
\hline
\end{tabular}

$\mathrm{h}_{\max }$-maximum jump height; $\mathrm{h}_{\min }$ - countermovement depth; $\mathrm{P}_{\max }$-maximum power; $\mathrm{P}_{\mathrm{av}}$-average power $\mathrm{VGRF}_{\max }$ - maximum vertical reaction force; $\mathrm{SI} \mathrm{VGRF}_{\max }$ - symmetry index of maximum vertical reaction force $\mathrm{I}_{\mathrm{ver}}$ - vertical component impulse; $\mathrm{SI}_{\mathrm{R}(\mathrm{t})}$ — symmetry index of ground reaction force; $\mathrm{I}_{\text {front }}$-frontal force impulse; $\mathrm{T}_{\text {ext }}$ - extensor muscle torque; $\mathrm{T}_{\text {flex }}$-flexor muscle torque; $\mathrm{SI}_{\text {ext }}$-symmetry index of extensor muscle torque; $\mathrm{SI}_{\text {flex }}$-symmetry index of flexor muscle torque; $\mathrm{H} / \mathrm{Q}$ ratio-flexor/extensor strength ratio; RoM $\mathrm{M}_{\text {pas }}-$ passive range of motion; $\mathrm{RoM}_{\mathrm{act}}$ - active ranges of motion; $\mathrm{SI}_{\mathrm{pas}}$ - symmetry index of passive range of motion; $\mathrm{SI}_{\mathrm{act}}-$ symmetry index of active range of motion.

Participants in cluster 1 had statistically significantly higher values of flexor muscle torques for both right $(\mathrm{F}=17.02 ; p<0.0001)$ and left $(\mathrm{F}=28.34 ; p<0.001)$ limbs. Posthoc tests confirmed the significance of these differences for the left limb between the participants from clusters: 1 ver $3(p=0.0002), 1$ ver $4(p=0.0001)$, and 3 ver $4(p=0.0003)$, and for the right limb between subjects from clusters: 1 ver $3(p=0.003), 1$ ver $4(p=0.0001)$, and 3 ver $4(p=0.003)$. ANOVA also showed that asymmetry SI $R(t)$ depended on the group (cluster) $\mathrm{F}=3.945 ; p=0.025$. Functional left-sided asymmetry of VGRF was found, while all cases of asymmetry of range of motion concerned right-sided asymmetry.

\section{Discussion}

Therefore, the aim of the current investigation was to assess the relationship between the flexor/extensor strength ratio and the range of motion of the knee joints and VGRF during jump in a sample of young healthy men. The data available in the literature on these relationships vary [6,19-25]. The authors of the present study expected that by comparing different types of symmetry based on a large group of participants $(n=64)$, it would be possible to detect unambiguous and statistically significant relationships.

The male participants were characterized by similar levels of jumping ability (approximately $0.43 \mathrm{~m}$ ) compared to physically active individuals in the study by Bailey et al. (approximately $0.40 \mathrm{~m}$ ) [20]. As non-athletes, they showed lower strength levels than professional athletes in the study by Drid et al. [4]. However, the level of strength symmetry in extensor muscles was comparable and lower in flexors. Despite the lack of limb asymmetry, the division of the participants by $\mathrm{H} / \mathrm{Q}$ ratio leads to several important conclusions. In the study group, $95 \%$ of people $(n=61$, see Figure 1 ) had symmetry of H/Q ratio. It has been shown in the literature that flexor strength is crucial for injury prevention and knee joint stability [2,4]. These comparisons indicate that the study group had biomechanical characteristics typical of young active men. However, it may appear that more than half of the subjects have a relatively disturbed $\mathrm{H} / \mathrm{Q}$ ratio (less than 0.5). Muscle imbalance among female athletes undergoing training to improve hamstrings relative to quadriceps strength has been shown to influence injury patterns [6]. Nosse [9] stated that the theory that the hamstrings are $60 \%$ stronger than the quadriceps thigh muscle was based on isometric measurement studies of the quadriceps and hamstrings of academic football players. It was demonstrated that the $\mathrm{H} / \mathrm{Q}$ ratio actually ranged widely from $47-75 \%$ to $43-90 \%$ when tested on isotonic and isokinetic devices, respectively, in different populations. Consequently, generalizing normative values for conventional indicators may be difficult because they may vary in different populations, ranges of motion (i.e., length/contraction relationships), and speed of motion (i.e., force/speed relationships) [9]. Therefore, the division made in this study based on the conventional $\mathrm{H} / \mathrm{Q}$ ratio does not suggest that the separated groups had disturbed $\mathrm{H} / \mathrm{Q}$ ratios. It was only intended as an attempt to indicate the effect of $\mathrm{H} / \mathrm{Q}$ ratio on the symmetry of VGRF and range of motion.

It was shown based on the analysis of variance ANOVA that the symmetry of VGRF depended on the group distinguished based on cluster analysis. Left-sided small asym- 
metry of VGRF was observed, while all cases of symmetry of range of motion and muscle strength concerned right-sided small asymmetry. However, this may indicate that the stronger limb did not determine the generation of higher ground reaction force (VGRF) and force impulse (I) values. There are studies showing a negative correlation between quadriceps/hamstrings muscle symmetry and SJ and CMJ jump performance [36]. Some studies have indicated that asymmetry of the opposite knee extensors has no effect on jump height [37]. The results of our research confirm the hypothesis of no such relationships. A study by Mertz et al. [38] showed that the weaker lower limb was not a stronger predictor of functional abilities compared to the stronger limb in older adults. This was also confirmed by the results obtained by LaRoche et al. [39]. In a theoretical asymmetric model, Yoshioka et al. [21] found that the stronger limb compensated for the strength deficit of the weaker side by lateral body movements to distribute the load in proportion to the muscle strength of each lower limb. This approach is consistent with the leading joint hypothesis $(\mathrm{LJH})$, which is based on the idea that the central nervous system uses the biomechanical properties of the limbs to organize movement [30]. According to this theory, one of the most influential biomechanical properties of human limbs is that they represent the connection of several segments. However, to explain the above case, the LJH would have to be extended to the biokinematic chain and one should accept that the acceleration/deceleration at the dominant (stronger) joint is due to reciprocal muscle activity on the weaker leg side. This mechanism works in the same way as during the movements of a single joint, that is, largely ignoring the effect of other joint movements. The development of LJH on both limbs assumes that the central nervous system, controlling movement, adjusts the stimulation of the muscular system to the capabilities of the weaker limb. In the case of CMJ vertical jump, the use of the full potential of the stronger lower limb would result in the loss of balance of the body during the take off and uncontrolled flight of the body to the side. Our results (Table 3) confirm this hypothesis.

The subjects from each cluster had a slightly greater strength of the extensors of the right knee joint. This tendency is also visible in the case of the mean values for the entire study group (Table 1; Text left $=246 \pm 52.4 \mathrm{Nm}$; Text right $=248 \pm 55.0 \mathrm{Nm}$ ). However, the muscles of the left lower limb generated a greater impulse of force during CMJ (Iver left $=433 \pm 70.7 \mathrm{Ns}$; Iver right $=430 \pm 65.2 \mathrm{Ns}$ ). Due to the fact that these differences are subtle, it is difficult to interpret unequivocally. In addition, the knee joint stability $(H / Q$ ratio) may have an impact on the magnitude of the generated vertical impulse of force (Iver). This proves, that the nervous system uses the weaker joint to control effectiveness of the movement during CMJ jump. As a consequence, also the jump height for persons from cluster 1 with the greatest asymmetry of $\operatorname{SIR}(t)$ is the lowest. However, it is possible that in this case, the significant asymmetry in the $H / Q$ ratio could also have influenced the jump height (Table 3). Therefore, further research and exploration on people with a clear asymmetry of limb strength in isometric and dynamic conditions are required.

\section{Conclusions}

Therefore, according to the authors, the reasons for the lack of relationship between the different types of symmetry should be attributed to the compensatory mechanisms that occur during motion control in dynamic movements such as CMJ jump. In conclusion, it can be stated that in young physically active men, the process of movement control by the nervous system compensates for the existing small asymmetries in the level of muscle strength of flexors and extensors of the knee joint and small asymmetries in the range of motion. The leading joint hypothesis can be used to explain the mechanisms of this compensation.

Author Contributions: Conceptualization: D.I., C.U., A.M. (Andrzej Mastalerz), A.M. (Anna Mazurkiewicz) and P.T.; methodology: D.I., C.U., A.M. (Andrzej Mastalerz), A.M. (Anna Mazurkiewicz) and P.T.; formal analysis: D.I., C.U., A.M. (Andrzej Mastalerz), A.M. (Anna Mazurkiewicz) and P.T.; investigation D.I., C.U., A.M. (Andrzej Mastalerz), A.M. (Anna Mazurkiewicz) and P.T.; resources: D.I., A.M. (Anna Mazurkiewicz) and P.T.; writing-original draft preparation: D.I., A.M. (Andrzej 
Mastalerz) and P.T.; writing—review and editing D.I., C.U., A.M. (Andrzej Mastalerz), A.M. (Anna Mazurkiewicz) and P.T.; supervision: D.I., C.U. and A.M. (Andrzej Mastalerz); project administration: D.I.; funding acquisition: D.I., C.U. and A.M. (Andrzej Mastalerz). All authors have read and agreed to the published version of the manuscript.

Funding: Scientific work was financed by the Ministry of Science and Higher Education in 2020/2022 as part of the Scientific School of the University of Physical Education in Warsaw-SN No. 5 "Biomedical determinants of physical fitness and sports training in adult population". This work was supported by the Ministry of Science and Higher Education (https:/ /www.gov.pl/web/nauka/) (accessed on 25 July 2021) (March 2020) in 2020/2022 as part of the Scientific School of the University of Physical Education in Warsaw-SN No. 5 "Biomedical determinants of physical fitness and sports training in adult population" and scientific program in the year 2018 (N RSA4 05354). The funders had no role in study design, data collection and analysis, decision to publish, or preparation of the manuscript.

Institutional Review Board Statement: The study was conducted in accordance with the Declaration of Helsinki, and the protocol was approved by the Ethics Committee of Józef Piłsudski University of Physical Education in Warsaw (SKE 01-04/2021, research project number N RSA4 05354).

Informed Consent Statement: Informed consent was obtained from all subjects involved in the study.

Data Availability Statement: The data presented in this study are available on request from the corresponding author. The data is not publicly available because the project it comes from is not completed.

Conflicts of Interest: The authors declare no conflict of interest.

\section{References}

1. Golik-Peric, D.; Drapsin, M.; Obradovic, B.; Drid, P. Short-term isokinetic training versus isotonic training: Effects on asymmetry in strength of thigh muscles. J. Hum. Kinet. 2011, 30, 29-35. [CrossRef] [PubMed]

2. Baratta, R.; Solomonow, M.; Zhou, B.H.; Letson, D.; Chuinard, R.; D'Ambrosia, R. Muscular coactivation. Am. J. Sports Med. 1988, 16, 113-122. [CrossRef]

3. Impellizzeri, F.M.; Rampinini, E.; Maffiuletti, N.; Marcora, S.M. A vertical jump force test for assessing bilateral strength asymmetry in athletes. Med. Sci. Sports Exerc. 2007, 39, 2044-2050. [CrossRef]

4. Drid, P.; Drapsin, M.; Trivic, T.; Lukač, D.; Obadov, S.; Milosevic, Z. Asymmetry of muscle strength in elite athletes. Biomed. Hum. Kinet. 2009, 1, 3-5. [CrossRef]

5. Makaruk, H.; Makaruk, B.; Sacewicz, T. Hamstring strength and flexibility asymmetry. Pol. J. Sport Tour. 2010, 17, 153-156.

6. Rosene, J.M.; Fogarty, T.D.; Mahaffey, B.L. Isokinetic hamstrings: Quadriceps ratios in intercollegiate athletes. J. Athl. Train. 2001, 36, 378-383.

7. Bennell, K.; Wajswelner, H.; Lew, P.; Schall-Riaucour, A.; Leslie, S.; Plant, D.; Cirone, J. Isokinetic strength testing does not predict hamstring injury in Australian rules footballers. Br. J. Sports Med. 1998, 32, 309-314. [CrossRef]

8. Steindler, A. Kinesiology of the Human Body under Normal and Pathological Conditions; Charles C Thomas: Springfield, IL, USA, 1955.

9. Nosse, L.J. Assessment of Selected Reports on the Strength Relationship of the Knee Musculature. J. Orthop. Sports Phys. Ther. 1982, 4, 78-85. [CrossRef]

10. Kannus, P. Isokinetic Evaluation of Muscular Performance. Endoscopy 1994, 15, S11-S18. [CrossRef]

11. Heiser, T.M.; Weber, J.; Sullivan, G.; Clare, P.; Jacobs, R.R. Prophylaxis and management of hamstring muscle injuries in intercollegiate football players. Am. J. Sports Med. 1984, 12, 368-370. [CrossRef] [PubMed]

12. Knapik, J.J.; Bauman, C.L.; Jones, B.H.; Harris, J.M.; Vaughan, L. Preseason strength and flexibility imbalances associated with athletic injuries in female collegiate athletes. Am. J. Sports Med. 1991, 19, 76-81. [CrossRef]

13. Nadler, S.F.; Malanga, G.A.; Feinberg, J.H.; Prybicien, M.; Stitik, T.P.; DePrince, M. Relationship between hip muscle imbalance and occurrence of low back pain in collegiate athletes. Am. J. Phys. Med. Rehabil. 2001, 80, 572-577. [CrossRef]

14. Beukeboom, C.; Birmingham, T.B.; Forwell, L.; Ohrling, D. Asymmetrical strength changes and injuries in athletes training on a small radius curve indoor track. Clin. J. Sport Med. 2000, 10, 245-250. [CrossRef] [PubMed]

15. Jordan, M.J.; Aagaard, P.; Herzog, W. Lower limb asymmetry in mechanical muscle function: A comparison between ski racers with and without ACL reconstruction. Scand. J. Med. Sci. Sports 2014, 25, e301-e309. [CrossRef]

16. LoTurco, I.; Pereira, L.A.; Kobal, R.; Abad, C.C.C.; Rosseti, M.; Carpes, F.; Bishop, C. Do asymmetry scores influence speed and power performance in elite female soccer players? Biol. Sport 2019, 36, 209-216. [CrossRef]

17. Tabor, P.; Mastalerz, A.; Iwańska, D.; Grabowska, O. Asymmetry Indices in female runners as predictors of running velocity. Pol. J. Sport Tour. 2019, 26, 3-8. [CrossRef] 
18. Sannicandro, I.; Rosa, R.; De Pascalis, S.; Piccinno, A. The determination of functional asymmetries in the lower limbs of young soccer players using the countermovement jump. The lower limbs asymmetry of young soccer players. Sci. Sports $\mathbf{2 0 1 2 , 2 7 ,}$ 375-377. [CrossRef]

19. Bishop, C.; Turner, A.; Read, P. Effects of inter-limb asymmetries on physical and sports performance: A systematic review. J. Sports Sci. 2017, 36, 1135-1144. [CrossRef]

20. Bailey, C.; Sato, K.; Alexander, R.; Chiang, C.-Y.; Stone, M.H. Isometric force production symmetry and jumping performance in collegiate athletes. J. Trainol. 2013, 2, 1-5. [CrossRef]

21. Yoshioka, S.; Nagano, A.; Hay, D.C.; Fukashiro, S. The effect of bilateral asymmetry of muscle strength on the height of a squat jump: A computer simulation study. J. Sports Sci. 2011, 29, 867-877. [CrossRef]

22. Bell, D.R.; Sanfilippo, J.L.; Binkley, N.; Heiderscheit, B.C. Lean mass asymmetry influences force and power asymmetry during jumping in collegiate athletes. J. Strength Cond. Res. 2014, 28, 884-891. [CrossRef] [PubMed]

23. Bailey, C.; Sato, K.; Burnett, A.; Stone, M.H. Force-production asymmetry in male and female athletes of differing strength levels. Int. J. Sports Physiol. Perform. 2015, 10, 504-508. [CrossRef]

24. Lockie, R.G.; Callaghan, S.J.; Berry, S.P.; Cooke, E.R.A.; Jordan, C.A.; Luczo, T.M.; Jeffriess, M.D. Relationship between unilateral jumping ability and asymmetry on multidirectional speed in team-sport athletes. J. Strength Cond. Res. 2014, 28, 3557-3566. [CrossRef]

25. Hoffman, J.R.; Ratamess, N.A.; Klatt, M.; Faigenbaum, A.D.; Kang, J. Do bilateral power deficits influence direction-specific movement patterns? Res. Sports Med. 2007, 15, 125-132. [CrossRef]

26. Moran, K.A.; Wallace, E. Eccentric loading and range of knee joint motion effects on performance enhancement in vertical jumping. Hum. Mov. Sci. 2007, 26, 824-840. [CrossRef]

27. Maloney, S.J.; Richards, J.; Nixon, D.G.D.; Harvey, L.J.; Fletcher, I.M. Vertical stiffness asymmetries during drop jumping are related to ankle stiffness asymmetries. Scand. J. Med. Sci. Sports 2016, 27, 661-669. [CrossRef] [PubMed]

28. Todorov, E. Optimality principles in sensorimotor control. Nat. Neurosci. 2004, 7, 907-915. [CrossRef] [PubMed]

29. Schmidt, R.A. A schema theory of discrete motor skill learning. Psychol. Rev. 1975, 82, 225-260. [CrossRef]

30. Dounskaia, N. Control of human limb movements: The leading joint hypothesis and its practical applications. Exerc. Sport Sci. Rev. 2010, 38, 201-208. [CrossRef]

31. Kaufman, K.R.; Miller, L.S.; Sutherland, D.H. Gait asymmetry in patients with limb-length inequality. J. Pediatr. Orthop. 1996, 16, 144-150. [CrossRef] [PubMed]

32. Herzog, W.; Nigg, B.M.; Read, L.J.; Olsson, E. Asymmetries in ground reaction force patterns in normal human gait. Med. Sci. Sports Exerc. 1989, 21, 110-114. [CrossRef]

33. Gajewski, J.; Michalski, R.; Buśko, K.; Mazur-Różycka, J.; Staniak, Z. Countermovement depth-A variable which clarifies the relationship between the maximum power output and height of a vertical jump. Acta Bioeng. Biomech. 2018, 20,127-134. [CrossRef]

34. Nigg, S.; Vienneau, J.; Maurer-Grubinger, C.; Nigg, B.M. Development of a symmetry index using discrete variables. Gait Posture 2013, 38, 115-119. [CrossRef] [PubMed]

35. Tabor, P.; Iwańska, D.; Grabowska, O.; Karczewska-Lindinger, M.; Popieluch, A.; Mastalerz, A. Evaluation of selected indices of gait asymmetry for the assessment of running asymmetry. Gait Posture 2021, 86, 1-6. [CrossRef]

36. Chan, K.M.; Maffulli, N.; Korkia, P.; Li, C.T. Principles and Practice of Isokinetics in Sports Medicine and Rehabilitation; Williams \& Wilkins: Hong Kong, China, 1996; pp. 117-122. ISBN 9623560168.

37. Sato, K.; Heise, G.D. Influence of weight distribution asymmetry on the biomechanics of a barbell back squat. J. Strength Cond. Res. 2012, 26, 342-349. [CrossRef] [PubMed]

38. Mertz, K.H.; Reitelseder, S.; Jensen, M.; Lindberg, J.; Hjulmand, M.; Schucany, A.; Andersen, S.B.; Bechshoeft, R.L.; Jakobsen, M.D.; Bieler, T.; et al. Influence of between-limb asymmetry in muscle mass, strength, and power on functional capacity in healthy older adults. Scand. J. Med. Sci. Sports 2019, 29, 1901-1908. [CrossRef] [PubMed]

39. LaRoche, D.P.; Villa, M.R.; Bond, C.W.; Cook, S.B. Knee extensor power asymmetry is unrelated to functional mobility of older adults. Exp. Gerontol. 2017, 98, 54-61. [CrossRef] 